\title{
ÍNDICE DE PRIORIZAÇÃO PARA AVALIAR A CONTENÇÃO VEGETATIVA EM TALUDE RODOVIÁRIO DE SAPROLITO DE GNAISSE, NA ZONA DA MATA DE MINAS GERAIS $\left({ }^{\mathbf{1}}\right)$
}

\author{
ROSILENE EINLOFT $\left({ }^{2}\right)$; HUGO ALBERTO RUIZ $\left(3^{*}\right)$; JAMES JACKSON GRIFFITH $\left({ }^{4}\right)$; \\ CARLOS ERNESTO GONÇALVES R. SCHAEFER $\left({ }^{3}\right)$; LIOVANDO MARCIANO DA COSTA $\left({ }^{3}\right)$
}

\begin{abstract}
RESUMO
O objetivo desse trabalho foi formular um índice de priorização para avaliar a contenção vegetativa em talude rodoviário de declividade acentuada subtrecho entre Viçosa e Araponga (MG), Brasil, a $20^{\circ} 44^{\prime}$ latitude S; 42 $50^{\prime}$ longitude W. Neste trabalho, os tratamentos consistiram de nove consórcios de uma gramínea (Brachiaria brizantha, Brachiaria decumbens ou Brachiaria ruziziensis) e uma leguminosa [mucuna preta (Stizolobium aterrimum), feijão guandu (Cajanus cajan) ou lablabe (Dolichos lab lab)]. Na elaboração do índice, o primeiro passo foi escolher, dentre as características analisadas, aquelas mais apropriadas para a seleção do consórcio no processo de revegetação estabelecendo, consequentemente, uma frequência por meio de uma matriz de ponderação. Ao término do exercício, a frequência com que uma característica foi assinalada, representa a importância individual na resposta global do consórcio aos tratamentos. A nota final de cada consórcio foi dada pelo somatório do produto das frequências multiplicadas pelos valores relativos das características determinadas experimentalmente. Após o cálculo, os índices foram analisados estatisticamente, aplicando-se o teste de agrupamento de Scott-Knott. Da análise do índice conjunto padronizado, pode-se concluir que a mucuna-preta foi a leguminosa mais apropriada no processo de revegetação, dentre as três testadas, com valor médio de 28,03 sobre máximo possível de 30 . O feijãoguandu revelou comportamento intermediário $(26,52)$ e o lab lab foi o menos indicado $(23,08)$. As características semelhantes de crescimento das braquiárias permitiram atestar respostas alternativas, dependendo da leguminosa associada. Assim, a Braquiaria brizanta foi a mais adequada para associação com a mucuna-preta, e a Braquiaria decumbens, quando em consórcio com o feijão-guandu.
\end{abstract}

Palavras-chave: seleção de espécies, gramíneas, leguminosas, recuperação de áreas degradadas.

$\left({ }^{1}\right)$ Parte da tese de doutorado, apresentada pela primeira autora à Universidade Federal de Viçosa. Recebido para publicação em 2 de janeiro de 2007 e aceito em 8 de setembro de 2008.

$\left(^{2}\right)$ Ambiente Gaia Consultoria, rua Otávio Silva Araujo, 72, 36570-000 Viçosa (MG). E-mail:reinloft@uol.com.br

$\left({ }^{3}\right)$ Departamento de Solos, Universidade Federal de Viçosa, 36571-000 Viçosa (MG). E-mail: hruiz@ufv.br (*) Autor correspondente; Carlos.Schaefer@ufv.br, liovandomc@yahoo.com.br

$\left({ }^{4}\right)$ Departamento de Engenharia Florestal, Universidade Federal de Viçosa. 36571-000 Viçosa (MG). E-mail: griffith@ufv.br 


\title{
ABSTRACT \\ PRIORIZATION INDEX TO EVALUATE VEGETATIVE CONTAINMENT OF A GNAISSE SAPROLITE ROADCUT IN THE ZONA DA MATA REGION, MINAS GERAIS STATE
}

\begin{abstract}
The objective of this study was to formulate a prioritization index to evaluate vegetative containment on a steep road cut alongside a highway connecting the towns of Viçosa and Araponga, Minas Gerais State, Brazil $\left(20^{\circ} 44^{\prime}\right.$ latitude S; $42^{\circ} 50^{\prime}$ longitude W). Treatments consisted of nine combinations of a grass (Brachiaria brizantha, Brachiaria decumbens or Brachiaria ruziziensis) and a legume (Stizolobium aterrimum, Cajanus cajan or Dolichos lab lab). In developing the index, first step was to choose, among the analyzed characteristics, those most appropriate to select combinations in the revegetation process, thereby establishing frequency by means of a weighted matrix. Upon concluding this exercise, the frequency assigned to the characteristic represents its individual importance in the overall consortium response to treatments. The final score for each consortium is the sum of the product of the frequencies multiplied by the relative values of the characteristics that were experimentally determined. Upon calculation, the indices were statistically analyzed, applying the Scott-Knott cluster test. It may be concluded from the joint standardized index that Stizolobium aterrimum was the most appropriate legume in the revegetation process among the three tested, with a mean value of 28.03 in a scale up to 30 . Cajanus cajan showed intermediate response (26.52) and Dolichos lab lab was the least successful (23.08). Similar growth characteristics for the brachiarias allow for alternative responses, depending on the associated legume. Therefore the Brachiaria brizantha was indicated as best for association with Stizolobium aterrimum and Brachiaria decumbens best in consortium with Cajanus cajan.
\end{abstract}

Key words: species selection, grasses, legume, degraded land reclamation.

\section{INTRODUÇÃO}

A abordagem dada pelo Departamento de Estradas de Rodagem para a contenção dos taludes rodoviários tem sido na maioria das vezes por meio de obras de geocontenção: camadas impermeabilizadoras, gabiões, muros de arrimo, escoamento de concreto entre outros. Medidas importantes para o processo, mas, quando utilizadas exclusivamente o resultado deixa a desejar.

Áreas com distúrbios podem ter a regeneração natural comprometida, e em algumas situações, não ocorrer ou se efetuar de forma lenta, deixando a superfície exposta aos agentes erosivos, acelerando ainda mais o processo de degradação (FrANCO et al., 1994). Para acelerar o processo, a implantação de cobertura vegetal é uma opção coerente e econômica. A vegetação atua no controle da erosão, amortecendo o impacto das chuvas, elevando a porosidade superficial, como barreira física ao transporte de material entre outros.

Dessa forma, a situação ideal não é escolher exclusivamente uma ou outra técnica de recuperação, ao contrário, é necessário usar e harmonizar as técnicas civis de contenção e medidas biológicas, a fim de obter resultados satisfatórios.

Na revegetação de áreas degradadas é necessário selecionar espécies adequadas a estabelecer-se e crescer em condições precárias de solo (Silva, 1993; Motta Neto, 1995, Einloft et al., 1999). De forma similar à seleção de espécies, é crescente o uso de medidas fisico-biológicas, as biomantas (SILVA, 1993, SouzA, 1997), que têm sido consideradas como uma das melhores maneiras para se recuperar encostas íngremes e agilizar o processo de sucessão ecológica (VALCARCEl e D' ALterio, 1998).

Pesquisas podem contribuir decididamente para essas e outras questões, porém, em alguns casos, não há resposta definitiva quanto aos melhores tratamentos. Em muitas situações, ao término de um trabalho experimental, o pesquisador se depara com dados estatísticos dispersos, pouco conclusivos e de difícil interpretação, principalmente quando considerada a complexidade do sistema em estudo. Apesar de ter sido observadas diferenças nos tratamentos aplicados, não é possível ao pesquisador combinar simultaneamente os dados obtidos, para indicar uma resposta mais sintética.

Outra questão a ser considerada é que uma prática de manejo ou conservação do solo, embora não intencional, pode resultar em mudanças positivas ou negativas no solo ou ainda as duas podem ocorrer simultaneamente, gerando mudança líquida no processo.

Nessa situação, um índice pode ser instrumento valioso como ferramenta de agregação que simplifica informações de naturezas diversas (SANDS e PADMORE, 2000) e permite conhecer a mudança líquida nas propriedades do solo, pois considera simultaneamente um conjunto de características analisadas experimentalmente. 
Em várias áreas, índices têm sido um importante instrumento de interpretação e análise de dados: recuperação de áreas degradadas (MustAFA, et al., 1990, Ruivo, 1991, EINLOFT, et al., 1999), manejo e conservação do solo (BOLINDER, et al., 1999, BURGER e Kelting, 1999), produtividade florestal (GALE et al., 1991, GAтTO, 2000) entre outros.

Neste trabalho, a proposta é um apelo ao Departamento de Estradas de Rodagem para a importância da revegetação para acelerar o processo de revegetação das áreas perturbadas e, conseqüentemente, a diminuição de quedas de barreiras nas estradas. Consciente de que um trabalho de revegetação não deve ter caráter imediatista, a recomendação de espécies deve ser criteriosa. Uma pesquisa que considere alterações nas propriedades do solo assim como a dinâmica da área em função das espécies recomendadas é de grande importância.

O objetivo deste trabalho foi formular um índice de priorização para avaliar a contenção vegetativa em um talude de declividade acentuada subtrecho entre Viçosa e Araponga (MG).

\section{MATERIAL E MÉTODOS}

O experimento foi implantado em dezembro de 1998 em talude de corte de Latossolo VermelhoAmarelo, gerado por ocasião da pavimentação da BR-482, no subtrecho entre Viçosa e Araponga (MG), Brasil, a $20^{\circ} 44^{\prime}$ latitude S; $42^{\circ} 50^{\prime}$ longitude W.

Os quatro blocos do experimento foram distribuídos em duas faces desse talude, com $75^{\circ}$ de inclinação. A localização das parcelas foi predominantemente em Horizonte $\mathrm{C}$, ficando algumas delas situadas em áreas de transição entre B e C. Os tratamentos, no esquema $1+3^{2}$, consistiram de uma testemunha e nove consórcios de uma gramínea (Brachiaria brizantha, Brachiaria decumbens ou Brachiaria ruziziensis) e uma leguminosa [mucuna preta (Stizolobium aterrimum), feijão guandu (Cajanus cajan) ou lablabe (Dolichos lab lab)]. A massa total de sementes por parcela sempre foi de $270 \mathrm{~g}$. As parcelas de $9 \mathrm{~m}^{2}(3 \times 3 \mathrm{~m})$, à exceção das testemunhas, foram coveadas. Nelas aplicou-se, a lanço, uma mistura de $63 \mathrm{~g}$ de 8-28-16, $225 \mathrm{~g}$ de calcário dolomítico e $5 \mathrm{~L}$ de esterco bovino, acrescida da mistura de sementes correspondente a cada tratamento.

Após a distribuição da mistura, as parcelas foram cobertas por tela ARP-430, uma biomanta resultante do entrelaçamento de fibras vegetais, a qual foi fixada na parcela por meio de grampos de aço.

Para avaliar a contribuição de cada consórcio para revegetação do talude em estudo foi feito acompanhamento periódico na área. Inicialmente, observou-se o tempo de germinação das espécies vegetais. Seis meses após a instalação do experimento, determinou-se a percentagem de cobertura vegetal e a produção de matéria seca da parte aérea de gramíneas, da parte aérea de leguminosas e de raízes de gramíneas e leguminosas.

Para a determinação da cobertura vegetal foi utilizado o "método dos pontos" (Mantovani, 1987). Dessa forma, 12 pontos foram amostrados em cada parcela. Nos locais de amostragem da cobertura vegetal na parcela, foi delimitada uma subparcela coletandose, separadamente, a parte aérea de gramíneas e de leguminosas e retirada de amostra de solo a $15 \mathrm{~cm}$ de profundidade. Nessa amostra separaram-se as raízes por meio de lavagem, utilizando peneiras de $0,25 \mathrm{~mm}$ de malha. Todos os materiais vegetais foram secos em estufa e pesados.

Para avaliar a contribuição de cada consórcio para revegetação do talude em estudo foi feito um acompanhamento periódico na área, sendo realizado três levantamentos em junho de 1999, agosto de 2002 e abril de 2003.

Para a seleção dos melhores tratamentos em cada um dos três levantamentos foi adaptado um índice formulado por EINLOFT et al. (1999), que considera simultaneamente um conjunto de características analisadas experimentalmente.

Na elaboração desse índice, o primeiro passo foi a escolha, dentre as características analisadas, aquelas mais apropriadas ao processo de revegetação de encostas, estabelecendo, em conseqüência, uma priorização. Foram propostos índices para os levantamentos de junho de 1999, agosto de 2002 e abril de 2003.

Para sistematizar a importância de cada característica, utilizou-se uma matriz de ponderação que adotou o método descrito por SinDEN e WORRELL (1979). Segundo o método, a interceptação de uma característica listada na linha, com outra característica listada na coluna, indica aos pesquisadores a característica de maior importância no desenvolvimento do consórcio, para a recuperação da área degradada (Tabela 1).

Ao término do exercício, a freqüência com que uma característica foi assinalada indica sua importância individual na resposta global do consórcio aos tratamentos. Considerando as características determinadas no levantamento de junho de 1999, os respectivos pesos foram: cobertura vegetal: 3 ; produção de matéria seca de parte aérea de leguminosa: 2; produção de matéria seca de parte aérea de gramínea: 1; e produção de raízes totais: 0 . Para não invalidar a característica raízes, com peso zero, o peso de todas as características foi incrementado em uma unidade, chegando-se aos valores de 4, 3, 2 e 1 para as freqüências das quatro características listadas, respectivamente (Tabela 1). 
Tabela 1. Matriz de ponderação e freqüência (f) da adaptabilidade dos consórcios, considerando as características vegetativas relacionadas aos tratamentos aplicados em junho de 1999

\begin{tabular}{lllllc}
\hline Característica & CV & PL & PG & R & $?$ \\
\hline Cobertura vegetal (CV) & CV & CV & CV & 3 & $\mathrm{f}=\sum+1$ \\
Parte aérea de leguminosas (PL) & & PL & PL & 2 & 3 \\
Parte aérea de gramíneas (PG) & & & PG & 1 & 2 \\
Raízes (R) & & & 0 & 1 \\
\hline
\end{tabular}

Nos levantamentos de agosto de 2002 e abril de 2003, as freqüências estabelecidas foram: leguminosa: 10, braquiária: 9, crosta microfítica: 8; espécies invasoras: 7; capim-gordura: 6; biomanta: 5; resíduos em decomposição: 4; crosta física: 3; solo exposto: 2; e erosão: 1 (Tabela 2). Não foi considerada a presença de rocha, por considerá-la característica própria da parcela experimental, sem resposta aos tratamentos aplicados.

Para o cálculo do índice, entretanto, é necessário fazer uma uniformização de escala. No levantamento de junho de 1999 não foi possível comparar quantitativamente a porcentagem de cobertura vegetal com a massa da matéria seca da parte aérea e das raízes. Em razão disso, no índice gerado aos seis meses, os valores de porcentagem de cobertura vegetal foram transformados em proporções, dividindo por 100. Os valores médios referentes à produção da parte aérea de braquiárias e leguminosas e de raízes foram transformados para uma escala universal de notas, de 0 a 1 , atribuindo-se valor unitário à maior produção de cada uma dessas características. Assim, um valor igual a 1 correspondeu à maior média verificada entre os tratamentos, e o valor 0 , à produção nula (Tabela 3).
Nos índices referentes aos levantamentos de agosto de 2002 e abril de 2003 utilizaram-se as proporções das tipologias (Tabela 4).

Realizado todo esse procedimento, a nota final de cada consórcio foi dada pelo somatório do produto entre a freqüência (Tabelas 1 e 2) e o valor médio de cada característica referente à calibração e uniformização de escalas (Tabelas 3 e 4).

Os resultados constantes para os índices de priorização foram submetidos à análise de variância, aplicando-se o teste de agrupamento de Scott-Knott.

\section{RESULTADOS E DISCUSSÃO}

No levantamento após seis meses de experimento, verificaram-se nos tratamentos apresentaram algumas diferenças estatisticamente significativas (Tabela 3). No entanto, analisando as características separadamente, não foi possível apontar os melhores consórcios. O índice de priorização possibilita combinar os resultados e indicar, de forma mais conclusiva, os consórcios mais apropriados.

Tabela 2. Matriz de ponderação e freqüência (f) da adaptabilidade dos consórcios, considerando as tipologias levantadas em agosto de 2002 e em abril de 2003

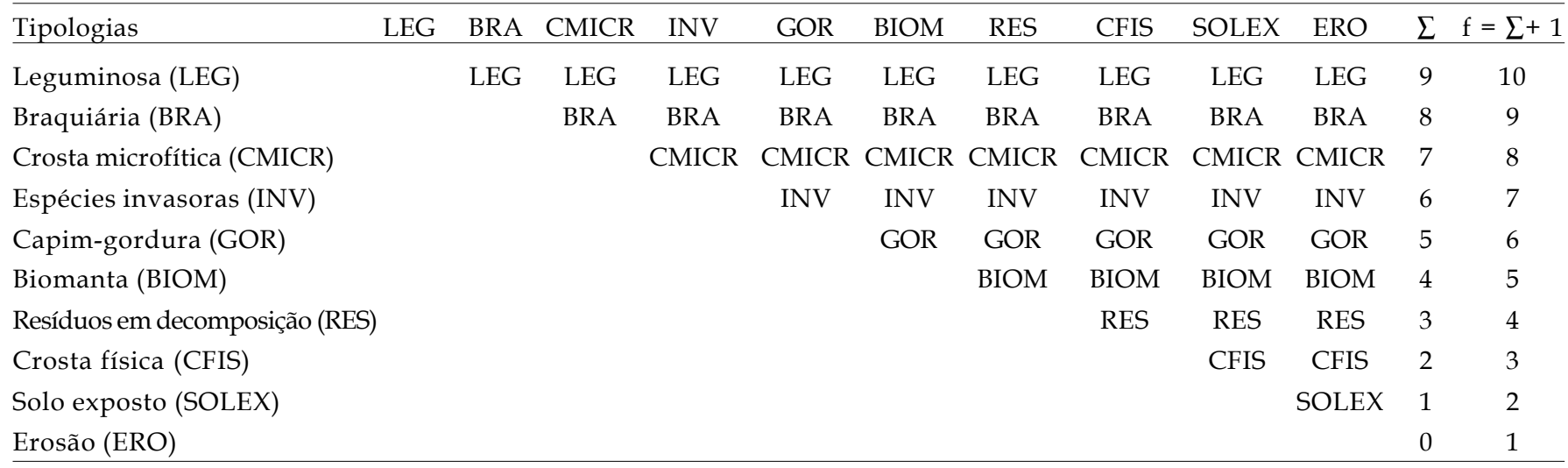


A nota final de cada consórcio foi dada pelo somatório do produto das freqüências (Tabela 1) e pelos valores relativos das características analisadas (Tabela 3):

IP: $(C V * 4)+(P L * 3)+(P G * 2)+(R * 1)$

Em que:

IP = índice de priorização

$\mathrm{CV}=$ cobertura vegetal

$\mathrm{PL}=$ parte aérea de leguminosas

PG = parte aérea de gramíneas
$\mathrm{R}$ = Raízes

Para braquiárias e leguminosas, os valores da produção de matéria seca da parte aérea foram calculados pela relação com o maior valor de produção total da parte aérea, correspondente ao consórcio de Braquiaria ruziziensis e mucuna $(302,00$ $+1493,41=1.795,41 \mathrm{~g} \mathrm{dm}^{-2}$. Para o valor relativo da produção de raízes, adotou-se a produção de raízes do consórcio Braquiaria ruziziensis e feijão-guandu como referência $\left(14,5 \mathrm{~g} \mathrm{dm}^{-3}\right.$, Tabela 3$)$. Os valores relativos são apresentados na tabela 3 .

Tabela 3. Valores absolutos e relativos da cobertura vegetal (CV), da produção de matéria seca de parte aérea de braquiárias (MSPAB), de leguminosas (MSPAL) e de raízes (MSR)

\begin{tabular}{|c|c|c|c|c|c|c|}
\hline \multirow{3}{*}{ Braquiária } & \multirow{3}{*}{ Leguminosa } & \multirow{3}{*}{$\mathrm{CV}$} & \multicolumn{3}{|c|}{ Produção de matéria seca } & \multirow{3}{*}{ Raízes } \\
\hline & & & \multicolumn{3}{|c|}{ Parte aérea } & \\
\hline & & & B & $\mathrm{L}$ & Total & \\
\hline \multirow{4}{*}{$\begin{array}{l}\text { B. brizanta } \\
(\mathrm{Bb})\end{array}$} & & $\%$ & \multicolumn{3}{|c|}{$-\mathrm{g} / \mathrm{dm}^{2}$} & $\mathrm{~g} / \mathrm{dm}^{3}$ \\
\hline & Stizolobium aterrimum (M) & 75 & 231 & 958 & 1190 & 11,6 \\
\hline & Cajanus cajan $(\mathrm{Fg})$ & 58 & 337 & 442 & 779 & 10,6 \\
\hline & Dolichos lab lab (Ll) & 58 & 443 & 5 & 447 & 9,2 \\
\hline \multirow{3}{*}{$\begin{array}{l}\text { B. decumbens } \\
(\mathrm{Bd})\end{array}$} & Stizolobium aterrimum (M) & 73 & 164 & 891 & 1055 & 11,4 \\
\hline & Cajanus cajan $(\mathrm{Fg})$ & 79 & 396 & 901 & 1297 & 9,2 \\
\hline & Dolichos lab lab (Ll) & 54 & 206 & 19 & 225 & 4,2 \\
\hline \multirow{3}{*}{$\begin{array}{l}\text { B. ruziziensis } \\
\text { (Br) }\end{array}$} & Stizolobium aterrimum (M) & 73 & 302 & 1493 & 1795 & 6,6 \\
\hline & Cajanus cajan $(\mathrm{Fg})$ & 81 & 410 & 568 & 978 & 14,5 \\
\hline & Dolichos lab lab (Ll) & 60 & 237 & 20 & 257 & 6,2 \\
\hline \multicolumn{7}{|c|}{ Valores relativos (adimensionais) } \\
\hline \multirow{3}{*}{$\begin{array}{l}\text { B. brizanta } \\
(\mathrm{Bb})\end{array}$} & Stizolobium aterrimum $(\mathrm{M})$ & 0.75 & 0.13 & 0.53 & 0,66 & 0.80 \\
\hline & Cajanus cajan $(\mathrm{Fg})$ & 0.58 & 0.19 & 0.25 & 0,44 & 0.73 \\
\hline & Dolichos lab lab (Ll) & 0.58 & 0.25 & 0.002 & 0,25 & 0.64 \\
\hline \multirow{3}{*}{$\begin{array}{l}\text { B. decumbens } \\
(\mathrm{Bd})\end{array}$} & Stizolobium aterrimum (M) & 0.73 & 0.09 & 0.50 & 0,59 & 0.79 \\
\hline & Cajanus cajan (Fg) & 0.79 & 0.22 & 0.50 & 0,72 & 0.63 \\
\hline & Dolichos lab lab (Ll) & 0.54 & 0.11 & 0.01 & 0,12 & 0.29 \\
\hline \multirow{3}{*}{$\begin{array}{l}\text { B. ruziziensis } \\
(\mathrm{Br})\end{array}$} & Stizolobium aterrimum (M) & 0.73 & 0.17 & 0.83 & 1,00 & 0.45 \\
\hline & Cajanus cajan $(\mathrm{Fg})$ & 0.81 & 0.23 & 0.32 & 0,55 & 1.00 \\
\hline & Dolichos lab lab (Ll) & 0.60 & 0.13 & 0.01 & 0,14 & 0.42 \\
\hline \multicolumn{7}{|c|}{ Contrastes Ortogonais } \\
\hline \multicolumn{2}{|c|}{$\mathrm{Bb}(\mathrm{M}+\mathrm{Fg}+\mathrm{Ll})+\mathrm{Bd}(\mathrm{M}+\mathrm{Fg}+\mathrm{Ll})-2 \mathrm{Br}(\mathrm{M}+\mathrm{Fg}+\mathrm{Ll})$} & -10 & -40 & -315 & -356 & 0.57 \\
\hline \multicolumn{2}{|c|}{$\mathrm{Bb}(\mathrm{M}+\mathrm{Fg}+\mathrm{Ll})-\mathrm{Bd}(\mathrm{M}+\mathrm{Fg}+\mathrm{Ll})$} & -4.9 & 82 & -135 & 54 & 2.21 \\
\hline \multicolumn{2}{|l|}{$\mathrm{Bb}(\mathrm{M}+\mathrm{Fg}-2 \mathrm{Ll})$} & 17 & $-318 \#$ & $1393^{*}$ & 1074\# & 3.71 \\
\hline \multicolumn{2}{|l|}{$\mathrm{Bb}(\mathrm{M}-\mathrm{Fg})$} & $17 \#$ & -106 & $518 \#$ & 412 & 0.97 \\
\hline \multicolumn{2}{|l|}{$\mathrm{Bd}(\mathrm{M}+\mathrm{Fg}-2 \mathrm{Ll})$} & $43^{*}$ & 148 & $1754^{*}$ & $1902^{*}$ & $12.13^{*}$ \\
\hline \multicolumn{2}{|l|}{ Bd (M-Fg) } & -6.3 & $-232 \#$ & -10 & -242 & 2.27 \\
\hline \multicolumn{2}{|l|}{$\mathrm{Bd}(\mathrm{M}+\mathrm{Fg}-2 \mathrm{Ll})$} & $33^{*}$ & 239 & $2003^{*}$ & $2259^{*}$ & $8.76 \#$ \\
\hline \multicolumn{2}{|l|}{ BR (M-Fg) } & -8 & -108 & $926^{*}$ & $817^{*}$ & $7.96^{*}$ \\
\hline
\end{tabular}

*, \# significativo a 5 e $20 \%$ de probabilidade, respectivamente, pelo teste $\mathrm{F}$. 


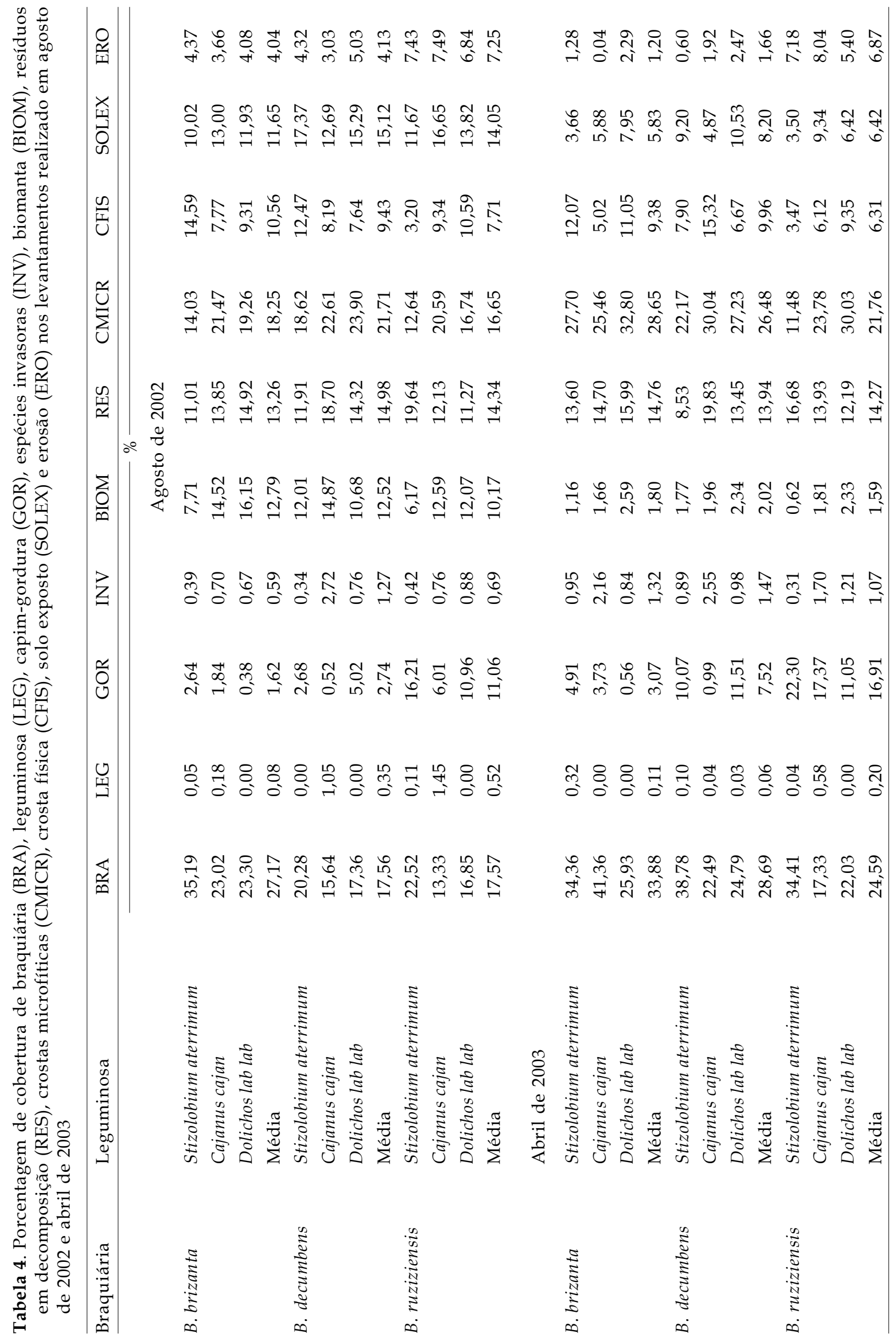


Obtém-se a título de exemplo o índice de priorização do consórcio entre a Braquiaria ruziziensis e a mucuna preta:

$$
\begin{aligned}
& \text { IP: }(C V * 4)+(P L * 3)+(P G * 2)+(R * 1) \\
& \text { IP: }(0,73 * 4)+(0,83 * 3)+(0,17 * 2)+(0,45 * 1) \\
& \text { IP: } 6,20
\end{aligned}
$$

Após o cálculo, os índices foram analisados estatisticamente, aplicando-se o teste de agrupamento de Scott-Knott (Tabela 5). A comparação dos índices confirmou a diferenciação entre leguminosas, mais que entre as braquiárias. Os consórcios com feijãoguandu e mucuna-preta foram, em geral, superiores aos que utilizaram o lablabe.

Tabela 5. Índice de prioridade de consórcios vegetais determinados em junho de 1999

\begin{tabular}{llc}
\hline Braquiária & Leguminosa & $\begin{array}{c}\text { Índice } \\
\text { de priorização }\end{array}$ \\
\hline B. ruziziensis & Stizolobium aterrimum & $6,20 \mathrm{a}$ \\
B. decumbens & Cajanus cajan & $5,73 \mathrm{a}$ \\
B. ruziziensis & Cajanus cajan & $5,66 \mathrm{a}$ \\
B. brizanta & Stizolobium aterrimum & $5,65 \mathrm{a}$ \\
B. decumbens & Stizolobium aterrimum & $5,39 \mathrm{a}$ \\
B. brizanta & Cajanus cajan & $4,18 \mathrm{~b}$ \\
B. brizanta & Dolichos lab lab & $3,46 \mathrm{~b}$ \\
B. ruziziensis & Dolichos lab lab & $3,11 \mathrm{~b}$ \\
B. decumbens & Dolichos lab lab & $2,70 \mathrm{~b}$ \\
\hline
\end{tabular}

Médias seguidas pela mesma letra não diferem estatisticamente entre si pelo teste de agrupamento de Scott-Knott, a $20 \%$ de probabilidade.

Considerando os índices de priorização, verifica-se que os consórcios que incluíram a mucunapreta não diferiram entre si, independentemente da braquiária associada (Tabela 5). Contudo, considerando valores absolutos desses índices, o consórcio com a Braquiaria ruziziensis seria a melhor opção. Esse índice é elevado, fundamentalmente, pela maior produção de matéria seca de parte aérea da leguminosa associada (Tabela 3). Pode-se concluir que, aos seis meses da instalação do experimento, os consórcios das braquiárias com a mucuna-preta e o feijão-guandu foram os mais apropriados, com destaque para a associação entre a Braquiária ruziziensis e a mucuna-preta.

De forma idêntica ao cálculo realizado no levantamento de junho de 1999, o índice de cada consórcio foi dado pelo somatório do produto das freqüências e os valores de ocorrência de cada tipologia. Vale ressaltar que os dados relativos à ocorrência das tipologias foram transformados em proporções, dividindo as porcentagens apresentadas na tabela 4 por 100 .

A freqüência para as tipologias LEG, BRA, CMICR, INV, GOR, BIOM, RES, CFIS, SOLEX e ERO diminuíram, nessa ordem, de 10 até 1 (Tabela 2).

$$
\mathrm{IP}=\begin{aligned}
& (L E G * 10)+(B R A * 9)+(C M I C R * 8)+\left(I N R^{*} 7\right)+(G O R * 6)+ \\
& (B I O M * 5)+(R E S * 4)+(C F I S * 3)+(S O L E X * 2)+(E R O * 1)
\end{aligned}
$$

Os critérios adotados para a hierarquização das tipologias levaram em consideração sua contribuição na recuperação de um talude degradado. Assim, logo após a abertura do talude, a revegetação do solo é primordial. Considerando as tipologias relacionadas com espécies vegetais, BRA, LEG, GOR e INV às leguminosas, foi atribuído a maior massa. Para isso, levou-se em consideração que, na fase inicial, nessas espécies havia características favoráveis, como elevada e rápida cobertura do solo e alta produção de material vegetal (parte aérea e raízes). Logo, imediatamente, listou-se a braquiária, com características iniciais pouco menos favoráveis que as indicadas para as leguminosas.

Indicaram-se, seguidamente, as crostas microfíticas, pelo seu papel pioneiro na colonização de áreas descobertas, propiciando a ocupação posterior por espécies vegetais (LeONARD, 1995). Às CMICR seguiram as invasoras, INV e GOR. A frequência de INV superou a de GOR, em razão da maior diversidade de espécies que contempla. Por outro lado, o capim-gordura possui características que podem dificultar a dinâmica vegetal, impedindo o crescimento de espécies mais adequadas ao processo de revegetação dos taludes (OzóRIO, 1997, BARTH, 1989).

O material orgânico em decomposição, BIO e RES, também foram citados, considerando-se que, como o nome indica, a expectativa é de permanência transitória no sistema. A biomanta teve precedência, por ser diretamente fixada no solo no momento de execução das obras para a contenção dos taludes. Em terrenos com declividades acentuadas, como a do talude utilizado no ensaio, os RESs, mais soltos, teriam maiores chances de ser removidos do sistema.

O solo descoberto é totalmente indesejável na contenção de encostas, porém sua presença é praticamente inevitável. Assim, das três situações levantadas, colocaram-se, em ordem decrescente, CFIS, SOLEX e ERO. Considerou-se que a crosta física, com o decorrente selamento da superfície do solo, conferiria certa proteção ao arraste de partículas (UsDA, 2001). Ademais, a degradação do SOLEX não seria tão acentuada como a do ERO. 
Após o cálculo do índice para cada tratamento, nos dois levantamentos realizados em agosto de 2002 e abril de 2003, foram analisados estatisticamente e não diferiram entre si pelo teste de Scott-Knott, a 20\% de probabilidade (Tabela 6), porém, não inviabiliza a utilização do índice. Deve-se considerar que diferenças estatisticamente significativas a, por exemplo, $50 \%$ revelam resposta em metade das situações analisadas. Como o custo de instalação é semelhante, não haveria razões para indicar que todos os tratamentos são iguais em locais com elevada variabilidade, como o aqui estudado.

Tabela 6. Índice de priorização de consórcios vegetais calculados para os levantamentos de agosto de 2002 e abril de 2003

\begin{tabular}{lll}
\hline BBraquiária & Leguminosa & $\begin{array}{c}\text { Índice } \\
\text { de priorização }\left({ }^{1}\right)\end{array}$ \\
\hline & Agosto de 2002 & \\
B. brizanta & Stizolobium aterrimum & 5,99 \\
B. brizanta & Cajanus cajan & 5,78 \\
B. brizanta & Dolichos lab lab & 5,67 \\
B. decumbens & Cajanus cajan & 5,56 \\
B. ruziziensis & Stizolobium aterrimum & 5,55 \\
B. decumbens & Dolichos lablab & 5,52 \\
B. decumbens & Stizolobium aterrimum & 5,34 \\
B. ruziziensis & Dolichos lab lab & 5,29 \\
B. ruziziensis & Cajanus cajan & 5,19 \\
& Abril de 2003 & \\
B. brizanta & Cajanus cajan & 7,07 \\
B. decumbens & Stizolobium aterrimum & 6,80 \\
B. brizanta & Stizolobium aterrimum & 6,75 \\
B. brizanta & Dolichos lab lab & 6,33 \\
B. ruziziensis & Stizolobium aterrimum & 6,32 \\
B. decumbens & Dolichos lab lab & 6,26 \\
B. ruziziensis & Dolichos lablab & 6,20 \\
B. decumbens & Cajanus cajan & 6,14 \\
B. ruziziensis & Cajanus cajan & 5,78 \\
\hline &
\end{tabular}

(1) Valores semelhantes pelo teste de Scott-Knott a $20 \%$.
$\mathrm{Na}$ tabela 6 verifica-se que os índices calculados em agosto de 2002 foram, no conjunto, inferiores àqueles de abril de 2003. A estação chuvosa levou ao crescimento das espécies vegetais e da crosta microfítica, com maior massa no índice. Por outro lado, no levantamento de agosto de 2002, a amplitude entre os índices foi de 0,75 e, em abril de 2003 , de 1,29 ,o que indicaria maior sensibilidade do índice calculado após a estação chuvosa.

Da comparação periódica de índices originados pelas mesmas variáveis, para a mesma época, pode inferir-se a evolução do processo de revegetação de taludes. Índices crescentes indicariam ampliação de condições favoráveis à contenção das encostas. Índices decrescentes, pelo contrário, indicariam o incremento dos fatores adversos. Nesse caso, poderia ser contemplada a necessidade de eventual plantio de manutenção.

A fim de padronizar os índices calculados nas três épocas, aos valores máximos de junho de 1999 $(6,20$ - Tabela 5), de agosto de 2002 (6,06 - Tabela 6) e de abril de 2003 (7,07 - Tabela 6) foram atribuídos o valor 10, calculando-se o restante de forma proporcional. Os valores resultantes e a soma dos índices nos três levantamentos são apresentados no tabela 7 .

A amplitude calculada para os índices de priorização padronizados revela que as maiores diferenças, entre os consórcios testados, ocorreram no período imediatamente após a instalação do ensaio (Tabela 7). Essa constatação sugere que nesse período estaria localizada a fase mais crítica no processo de contenção de encostas, o que pode ser comprovado com os consórcios que incluíram o lablabe. Essa leguminosa saiu do sistema antes dos seis meses do levantamento inicial (junho de 1999) e proporcionou os menores valores, com reflexo no índice total padronizado (Tabela 7).

Tabela 7. Índices de priorização padronizados de consórcios vegetais calculados para os levantamentos de junho de 1999, agosto de 2002 e abril de 2003

\begin{tabular}{|c|c|c|c|c|c|}
\hline Braquiária & Leguminosa & 06/1999 & $08 / 2002$ & $04 / 2003$ & Soma \\
\hline B. brizanta & Stizolobium aterrimum & 9,11 & 10,00 & 9,55 & 28,66 \\
\hline B. ruziziensis & Stizolobium aterrimum & 10,00 & 9,27 & 8,94 & 28,21 \\
\hline B. decumbens & Stizolobium aterrimum & 8,69 & 8,91 & 9,62 & 27,22 \\
\hline B. decumbens & Cajanus cajan & 9,24 & 9,28 & 8,68 & 27,20 \\
\hline B. brizanta & Cajanus cajan & 6,74 & 9,65 & 10,00 & 26,39 \\
\hline B. ruziziensis & Cajanus cajan & 9,13 & 8,66 & 8,18 & 25,97 \\
\hline B. brizanta & Dolichos lab lab & 5,58 & 9,47 & 8,95 & 24,00 \\
\hline B. ruziziensis & Dolichos lab lab & 5,02 & 8,83 & 8,77 & 22,62 \\
\hline B. decumbens & Dolichos lab lab & 4,35 & 9,22 & 8,85 & 22,62 \\
\hline Amplitude & - & 5,65 & 1,34 & 1,82 & 6,24 \\
\hline
\end{tabular}


Pelos resultados constantes da tabela 7 , observa-se, também, a importância de utilização do índice que, nesse ensaio de longa duração, permitiu apontar a mucuna-preta como a leguminosa mais apropriada ao processo de revegetação, entre as três testadas. O comportamento de feijão-guandu foi intermediário.

As características semelhantes de crescimento das braquiárias permitem apontar respostas alternativas, dependendo da leguminosa associada. Assim, a Braquiaria brizanta é mais adequada à associação com a mucuna-preta, e a Braquiaria decumbens, quando em consórcio com o feijão-guandu (Tabela 7).

Os resultados dos levantamentos realizados em junho de 1999, agosto de 2002 e abril de 2003 permitem indicar a mucuna-preta como a leguminosa mais apropriada e, em consórcio, a associação com a braquiária brizanta como a mais efetiva.

\section{CONCLUSÕES}

1. A mucuna-preta foi a leguminosa mais apropriada no processo de revegetação, entre as três testadas. O comportamento de feijão-guandu foi intermediário e o lablabe, o de menor crescimento.

2. As características semelhantes de crescimento das braquiárias permitiram respostas alternativas, dependendo da leguminosa associada. Assim, a Braquiária brizanta foi mais adequada para associação com a mucuna-preta, e a Braquiária decumbens, quando em consórcio com o feijão-guandu.

\section{REFERÊNCIAS}

BARTH, R.C. Avaliação da recuperação de áreas mineradas no Brasil. Viçosa:MG: Sociedade de Investigações florestais, Departamento de Engenharia Florestal/UFV, Instituto Brasileiro de Mineração- IBRAM, Comissão Técnica de Meio ambiente, 1989. 41p. (Boletim técnico, 1)

BOLINDER, M.A.; ANGERS, D.A.; GREGORICH, E.G.; CARTER, M.R. The response of soil quality indicators to conservation management. Canadian Journal Soil Science, Otawa, n.79, p.37-45, 1999.

BURGER, J.A.; KELTING, D.L. Using soil quality indicators to assess forest stand management. Forest Ecology and Management, Amsterdam, n.122, p.155-166, 1999.

EINLOFT, R.; GRIFFITH, J.J.; RUIZ, H.A. Índice de priorização de gramíneas e leguminosas para revegetação de área de empréstimo. Revista Árvore, Viçosa, n.23, p.213-221, 1999.
FRANCO, A.A., CAMPELLO, E.F., DIAS, L.E., FARIA, S.M. Revegetação de áreas de mineração de bauxita em Porto Trombetas- PA com leguminosas arbóreas noduladas e micorrizadas. In: RECUPERAÇÃO DE ÁREAS DEGRADADAS. SIMPÓSIO SUL - AMERICANO, 1: SIMPÓSIO NACIONAL, 2, 1994, Curitiba, PR. Anais... Curitiba: Fundação de Pesquisas Florestais - FUPEF, 1994. p.145-153.

GALE, M.R.; GRIGAL, D.F.; HARDING, R.B. Soil, productivity index: preditions of site quality for white spruce plantations. Soil Science Society of America Journal, Madison, n.55, p.17011708, 1991.

GATTO, A. Manejo do solo em áreas de reforma de floresta de eucalipto e seus reflexos na produtividade. 2000. 62f. Dissertação (Solos e Nutrição de Plantas) - Universidade Federal de Viçosa, Viçosa.

LEONARD, S.G.; ROSENTRETER, R.; KARL, M.G. Microbiotic crusts: ecological roles and implications for rangeland management in the interior Columbia Basin and portions of the Klamath and Great Basin. 1995. 26p. Disponível em: < www.icbemp.gov/science/leonard2.pdf> Acesso em 12 de fevereiro de 2003.

MANTOVAM, W. Análise florística e fitossociológica do estrato herbáceo subarbustivo do cerrado na reserva biológica de Mogi Guaçu e em Itirapina, SP. 1987. 166f. Dissertação (Mestrado em Ecologia) - Unicamp, Campinas.

MOTTA NETO, J.A.; MORAES, A.de; PREDEVELHO, B.M. Recuperação de um solo degradado pela mineração do xisto através do uso forrageiras e de adubações . In: CONGRESSO BRASILEIRO DE CIENCIA DO SOLO, 25., Viçosa, 1995. Programas e Resumos... Campinas, SBCS, 1995. p.2025.

MUSTAFA, G.; DILLAHA, T.A.; SARIN, S.C.; DANIELS, W.L. \& MOSTAGHIMI, S. Revegetation of reclaimed mine soils under weather uncertainty: a stochastic dynamic optimization approach. Resource Management and Optimization, Wageningen, n.8, p.15-30,1990.

OZÓRIO, T.F. Avaliação da recuperação de taludes usando sacos de aniagem em configuração de malha. Viçosa, Universidade Federal de Viçosa, 1997, 35p. Monografia de Graduação).

RUIVO, M.L.P. Caracterização das condições edáficas do Latossolo Amarelo textura muito argilosa após mineração de bauxita em Porto Trombetas-Oriximiná-Pará. Belém: Faculdade de Ciências agrárias do Pará, 1991. 199 p. Dissertação (Ciência do Solo).

SANDS, G.R.; PODMORE, T.H. A generalizaed environmental sustainability index for agricultural systems. Agriculture Ecosystem and Environment, Amsterdam n.79, p.29-41, 2000.

SILVA, A.L.O. Uso de sacos de aniagem para revegetação de taludes na Ferteco Mineração S.A. Viçosa, MG: Sociedade de Investigações Florestais, 1993. 8p. (Informativo SIF, 1)

SINDEN, J.A.; WORRELL, A.C. Unpriced values. New York: John Wiley, 1979. 511p. 
SOUZA, M.G. Revegetação de taludes com material geotêxtil em área minerada. Viçosa: Universidade Federal de Viçosa, 1997. 47 p. Dissertação (Ciência Florestal)

USDA: United States Department of Agriculture. Physical and biological soil crusts. Washington: Secretary of Agriculture, 2001. 2p.

VALCARCEL, R.; D'ALTERIO, C.F.V. Medidas físico-biológicas de recuperação de áreas degradadas: avaliação das modificações edáficas e fitossociológicas. Floresta e Ambiente, Seropédica, n.5, p.68-88, 1998. 